\title{
Microbial metabolites in nutrition, healthcare and agriculture
}

\author{
Rajendra Singh $^{1} \cdot$ Manoj Kumar $^{1} \cdot$ Anshumali Mittal $^{2} \cdot$ Praveen Kumar Mehta $^{3}$
}

Received: 26 August 2016/ Accepted: 7 December 2016/Published online: 8 April 2017

(c) The Author(s) 2017. This article is an open access publication

\begin{abstract}
Microorganisms are a promising source of an enormous number of natural products, which have made significant contribution to almost each sphere of human, plant and veterinary life. Natural compounds obtained from microorganisms have proved their value in nutrition, agriculture and healthcare. Primary metabolites, such as amino acids, enzymes, vitamins, organic acids and alcohol are used as nutritional supplements as well as in the production of industrial commodities through biotransformation. Whereas, secondary metabolites are organic compounds that are largely obtained by extraction from plants or tissues. They are primarily used in the biopharmaceutical industry due to their capability to reduce infectious diseases in human beings and animals and thus increase the life expectancy. Additionally, microorganisms and their products inevitably play a significant role in sustainable agriculture development.
\end{abstract}

Keywords Microorganisms - Metabolites - Healthcare · Agriculture $\cdot$ Nutrition $\cdot$ Supplements

Anshumali Mittal

anshumalijnu@gmail.com

Praveen Kumar Mehta mehtapkbiotech@gmail.com

1 Department of Biochemistry, VP Chest Institute, University of Delhi, Delhi 110007, India

2 Mill Hill Laboratory, Division of Structural Biology and Biophysics, The Francis Crick Institute, London, UK

3 Centre for Molecular Biology, Central University of Jammu, Raya-Suchani, Bagla, Dist. Samba, J\&K 181143, India

\section{Introduction}

Microorganisms are of immense importance to environment and essential to all life forms, and are primary source of nutrients and act as chief recycler in environment (Bisen et al. 2012). Microorganisms are present in extremely large sphere of environment and thrive from abyssal zone to stratosphere (at heights up to $60 \mathrm{~km}$ ) and in a wide range of temperatures ranging from arctic ice to boiling volcanoes (Imshenetsky et al. 1978; Wainwright et al. 2006). These microscopic organisms are used in the preparation of variety of foods and also used as a source of food and feed supplements. For example, amino acids are obtained from Corynebacterium, Brevibacterium and Escherichia coli; vitamins from Propionibacterium and Pseudomonas; organic acids from Aspergillus, Lactobacillus, Rhizopus, and enzymes from Aspergillus, Bacillus (Shimizu 2001; Gurung et al. 2013; Mahmood 2015; Sun et al. 2015). Microbes have been recognized considerably for their potential in the development of bioprocess technologies for unhindered production of food products and supplements to meet increasing demand by continuously growing world population. In addition, microorganism-based methodologies do not constitute a major source of pollution, and therefore, are preferred alternative for overcoming serious environmental problems, which arise from the conventional chemical methods.

According to Business Communication Company (BCC), the total global market for microbes and microbial products was estimated at nearly $\$ 143.5$ billion in 2014 , and is expected to reach nearly $\$ 306$ billion at a compound annual growth rate (CAGR) of approximately $14.6 \%$ over the period from 2015 to 2020 (Microbial Products 2015). New technologies for the production of microbial products are replacing synthetic production processes due to 
technical and economical advantages. These products include nutrition supplements such as, vitamins and amino acids, organic acids, agriculturally important metabolites, enzymes, flavoring agents, coloring agents and pharmaceutical products (Demain 2007). Healthcare was the largest end-user market for microbes and microbial products at about $\$ 100.4$ billion in 2014 , and expected to increase to nearly $\$ 111.5$ billion by 2015 , and over $\$ 187.8$ billion by 2020. The large size of the healthcare market reflects the importance of microbe-based biopharmaceutical industry (Microbial Products 2015).

Primary metabolites include amino acids, nucleotides, and fermentation end products such as ethanol and organic acids, which are considered essential for proper growth of microorganisms. Microbial synthesis is becoming the dominant and optimal process for amino acid production because of its ease to produce enantiomerically pure amino acids at low cost and ecological acceptability (Sun et al. 2015). Secondary metabolites are organic compounds that form at the end or near the stationary phase of growth, and are not directly associated with growth, development, and reproduction of microorganisms. These products are largely involved in healthcare activities as antimicrobial agents, antiparasitic agents, antitumor, enzyme inhibitors and immunosuppressive etc. (Demain 1999).

The serendipitous discovery of antibiotic penicillin by Fleming in 1929 has drawn the interest of scientists to investigate the therapeutic role of microbial products for combating life-threatening infections. This lead to mass production of antibiotics during World War II by surface culture techniques and the period till 1960 was called as golden age of antibiotics. For the discovery and concept of antibiotics in infectious disease therapy Alexander Fleming, Howard Florey and Emst Boris Chain shared Nobel Prize in physiology/medicine in 1945. Since then, a large number of soil as well as marine microorganisms have been explored for their inexhaustible involvement in pharmaceutical industry. The products derived from microbes are inevitably used to control and cure many infectious diseases acting as antibacterials, cholesterol lowering agents, immunosuppressants, anthelmintics and antiparasitic drugs (Demain and Sánchez 2009).

Secondary metabolites with activities as plant growth stimulants, herbicides and insecticides have also been reported. Some metabolites, such as adriamycin, bleomycin, daunomycin, and mithramycin were used as antitumor compounds (Kieslich 1986). In addition, secondary metabolites are also used as anesthetics, anti-inflammatory agents, anti-coagulants, anabolics, hemolytics, hypocholesterolemics and vasodilatories (Bentley 1997). Different strategies have been considered for effective and overproduction of primary metabolites, where genetic and physiological manipulations have played a significant role.
These methods include over-expression of genes involved in metabolite synthesis, knockout of genes involved in degradation, over expression of associated coenzymes and continuous extraction of metabolites from the culture (Tamano 2014).

In this communication, we are precisely illustrating the roles of microbial metabolites in nutrition, healthcare and agriculture with their current industrial status. The role of microorganisms as a potential source of food and feed supplements, and antimicrobial and antitumor properties in healthcare are emphasized.

\section{Amino acids}

The amino acids are building blocks of protein molecules and hence used in dietary and feed supplements of human and animals, respectively (Mahmood 2015). These organic molecules have various role, such as animal feed additives (lysine, methionine, threonine), flavor enhancers (aspartic acid, monosodium glutamate, serine), antioxidants (cysteine, L-tryptophan and L-histidine), as sweeteners (aspartame made from aspartic acid and phenylalanine), and ingredients in cosmetic and medicinal products (Bommarius et al. 1998; Ikeda 2003; Mueller and Huebner 2003; Leuchtenberger et al. 2005; Park and Lee 2008; Ivanov et al. 2014). Additionally, amino acids are suggested as dietary supplements for body building, bruxism, depression, sleep aid, premenstrual dysphoric disorder, attention deficit-hyperactivity disorder, and smoking cessation. Nonessential amino acids can be synthesized by human body but essential amino acids cannot be synthesized in human body but are required for protein synthesis and therefore, dietary supplement is necessary from external sources. Hence, production of essential amino acids at industrial scale using microbial sources is promising and desirable. The worldwide production technology for amino acids is dominated by microbial fermentation and enzymatic processes owing to cost-effectiveness, ecological acceptability and ease to produce enantiomerically pure amino acids (Ikeda 2003; Becker and Wittmann 2012).

The worldwide production of amino acids was about 6.5 million tons in 2014 and is expected to reach 10 million tons of value nearly $\$ 35$ billion by 2022 (Amino Acids Market 2015). The commercial production through fermentations and enzymatic transformations mainly use Corynebacterium glutamicum and Escherichia coli to produce L-glutamic acid (monosodium glutamate), L-aspartic acid, Lphenylalanine, L-lysine, L-methionine, L-threonine, and Ltryptophan. L-lysine is a preferred additive to animal feed and approximately, 1.3 million tons of lysine is produced annually through microbial fermentation using $C$. glutamicum (van Ooyen et al. 2012; Sun et al. 2015). 
L-Glutamate, extensively used in food and beverage industry as flavor enhancer, was accounted for almost $40 \%$ of whole amino acids volume in 2014. The global L-glutamate market was valued over $\$ 8.0$ billion in 2014 due to increased application in food and beverages industries as flavor enhancer and in $\mathrm{pH}$ regulation (Amino Acids Market 2015). L-Glutamate is a vital element of aged or fermented foods, such as cheese and soy sauce. Microorganisms of the genus Brevibacterium, Corynebacterium, Micrococcus and Microbacterium are used for the fermentative production of glutamate (Sanchez and Demain 2008; Mahmood 2015). The chief amino acids used as animal feed additives are lysine, methionine, threonine and tryptophan. The increasing demand of these amino acids are coupled with rising meat consumption as these feed ingredients are essential for good health and regulate metabolic processes of the livestock, such as swine, broiler and cattle to gain faster growth and appropriate weight (Amino Acids Market 2015)

Animal feed was reported as the largest consumer of Llysine and accounted for approximately $92 \%$ of total market volume in 2013. The world market of L-lysine is expected to reach 2.8 million tons of value nearly $\$ 7$ billion by 2020, at a CAGR of $6.0 \%$ from 2014 to 2020 (Lysine market analysis 2014). L-glutamate and L-lysine, main food flavoring and feed ingredients, were produced over 5 million tons in 2013 and the industrial market for amino acids is increasing at a yearly growth rate of 6-8\% (Becker and Wittmann 2012; Wendisch 2014; Sun et al. 2015). Aromatic amino acids, such as L-tyrosine, L-phenylalanine and L-tryptophan, are vital amino acids for human diet and important precursors for the production of high value byproducts (nitric oxide, polyamines, glutathione, taurine, thyroid hormones, serotonin etc.) (Polen et al. 2005; Sun et al. 2015). The leading manufacturers worldwide are Cargill, Novus, Ajinomoto, ADM, Evonik, DSM and Prinova (Amino Acids Market 2015). The microbial technology has made a significant progress for large-scale amino acids production to meet unhindered supply for increasing demands, using constantly improving biotechnology manufacturing methods involving genetic and metabolic engineering and physiologically manipulations (Barker and Campbell 1981; Wang et al. 2001; Hartmann et al. 2003; Znad et al. 2004; Demain 2007).

\section{Vitamins}

Vitamins are essential micronutrients required in trace amount to maintain normal physiological function of the body. These vital nutrients are not synthesized by mammals, and therefore, dietary supplement is necessary from external sources to maintain the balanced metabolism in all living organisms (Shimizu 2001; Gupta and Gupta 2015). Some vitamins are required as coenzymes to facilitate the biochemical reactions catalyzed by the enzymes. Vitamin $\mathrm{K}$ is required for normal blood clotting and also to activate receptor to facilitate transcription mechanisms in bone tissues, and to treat osteoporosis (Berg et al. 2002; Bolander 2006). Vitamin A is required as precursor to rhodopsin and other visual pigments, and also associated with specific gene transcription activation that facilitates growth and development (Berg et al. 2002). Vitamins are produced during regular metabolism of microorganisms and widely used as food additives, health supplements, and therapeutic agent etc. Vitamins are produced commercially either through direct fermentation or combined chemical and microbiological processes using appropriate microorganisms (Shimizu 2001; Bhalla et al. 2007). According to a Global Strategic Business Report, the global market of vitamins is expected to reach over $\$ 9.0$ billion by 2020 due to increasing health awareness and adoption of precautionary healthcare practices (Vitamins 2015).

Riboflavin (vitamin $\mathrm{B}_{2}$ ), a water soluble vitamin, is essential for growth and reproduction in humans and animals. Vitamin $B_{2}$ deficiency results in cheilosis and dermatitis in humans. The annual production was estimated 4.6 million $\mathrm{kg}$ and the leading producer of riboflavin are Hoffmann-La Roche (Switzerland), BASF (Germany), ADM (USA), Takeda (Japan) (Demain 2007). The chief microorganisms used in the fermentative production of riboflavin are two closely related ascomycetes, Eremothecium ashbyii and Ashbya gossypii. A. gossypii is an efficient and preferred source of riboflavin production as it can produce 40,000 times more vitamin than required for its own growth. Genetically engineered Bacillus subtilis and Corynebacterium ammoniagenes are other bacterial species preferred for riboflavin biosynthesis (Survase et al. 2006).

Cyanocobalamin (vitamins $\mathrm{B}_{12}$ ), an anti-pernicious anemia factor, is required in trace amounts (almost $1 \mu \mathrm{g} /$ day) and produced commercially exclusively by fermentation process using Propionibacterium shermanii and Pseudomonas denitrificans. These microbes manufacture 100,000 times more vitamin than they require for their own growth (Kusel et al. 1984; Spalla et al. 1989; Demain 2007).

$\beta$-Carotene, pro-vitamin $\mathrm{A}$, is required for vision, proper growth and reproduction. The deficiency or malabsorption of vitamin A causes night blindness, changes in the skin and mucosal membranes (http://www.fao.org/docrep/004/ y2809e/y2809e0d.htm). The microorganisms Blakeslea trispora, Phycomyces blakesleeanus, Mucor circinelloides, Rhodotorula spp. and Choanephora cucurbitarum are used for the production of $\beta$-carotene. Among these microbial strains, Blakeslea trispora and Phycomyces blakesleeanus are preferred and used for the industrial production by 
submerged fermentation due to high yield of $\beta$-carotene (Wang et al. 2012; Mata-Gomez et al. 2014).

\section{Enzymes}

Catalytic activities of microbes have been utilized since ancient times for production of bread, wine, and beer. Enzymes derived from microorganisms have drawn significant attention for extensive applications in food, chemical and healthcare industries due to ease of production, stability, and other technical advantages and therefore, microorganisms are utilized in industries as the preferred source of enzymes than other sources of enzymes production, such as animals and plants The use of biocatalytic activities in several industries including food, feed, leather, textiles are increasing rapidly due to time saving process, cost effectiveness, biodegradable nature and environmental friendly characteristics (Gurung et al. 2013; Adrio and Demain 2014; Singh et al. 2016). Besides, microbial enzymes are also involved in the potential degradation of toxic chemical compounds, such as phenolic compounds, nitriles, amines etc. of industrial and domestic wastes ( $\mathrm{Li}$ et al. 2012; Choi et al. 2015). The biotechnological developments have led to the manipulation of the microorganisms through recombinant DNA technology, protein engineering and their production in appropriate quantities to meet the demand (Liu et al. 2013). According to a market analysis, the global market of industrial enzymes was estimated $\$ 4.2$ billion in 2014 and is predicted to grow at compound annual growth rate (CAGR) of 7\% from 2015 to 2020 (Industrial Enzymes Market 2015). In healthcare industries, enzymes are used in therapeutic management of health disorders caused due to enzyme deficiencies in humans (Vellard 2003; Anbu et al. 2015).

For example, phenylalanine ammonia lyase is used in degradation of phenylalanine in persons with inherited phenylketonuria disorder (Sarkissian et al. 1999). Besides, sacrosidase ( $\beta$-fructofuranoside fructohydrolase) enzyme is given to facilitate digestion of sucrose in patients with genetic congenital sucrase-isomaltase deficiency as they are incapable of digesting sucrose (Treem et al. 1999). Utilization of microbial enzymes for different purposes in food, pharmaceutical, textile, paper, leather, and other industries are extensive and incessantly increasing over conventional methods owing to higher effectiveness. Table 1 illustrated applications of few enzymes and their function in respective industries (Kamini et al. 1999; Gurung et al. 2013; Adrio and Demain 2014).

The prospects of enzymes of microbial origin for industrial applications have grown significantly in the 21 st century and their valuable contribution in food industry may be used to meet incessantly growing demand of food supply for rapidly growing population. Furthermore, these are used in development of alternative fuel supply to overcome the issues associated with depletion of natural resources and in the development of green environment.

\section{Organic acids}

Organic acids are among the most versatile ingredients in food, beverages, pharmaceuticals, solvents, petrochemicals, textile, detergents, detergents, pharmaceuticals, rubber, perfumes, plastics, dyes and adhesives (Sun et al. 2015). In addition, they are used widely in the production of chemicals that are utilized in the automotive and construction industries. The catalytic potential of microbes is used in commercial production of several organic acids, such as acetic acid, lactic acid, gluconic acid, citric acid (Sauer et al. 2008). Global market of organic acids was estimated at approximately $\$ 12$ billion in 2014 and is expected to reach over $\$ 18$ billion by 2023. Increasing demand of vinyl acetate monomer in food packaging industry and high growth of pharmaceutical industry are among major driving factors for huge growth in market (Carboxylic Acid Market 2015).

Citric acid is used for a wide range of applications in food industries, such as acidulant, flavorant, preservatives, sequestrant, emulsifiers, and buffering agent. The global market of citric acid was $\$ 2.6$ billion in 2014 and is expected to reach $\$ 3.6$ billion by 2020 at a CAGR of $5.5 \%$ from 2015 to 2020 (Citric Acid Market 2015). Incessant growth in the production of citric acid is linked with increasing demands in food, beverages, cosmetic industries and personal care products. About $99 \%$ production of total citric acid occurs via microbial processes using surface or submerged cultures and approximately, 70\% citric acid of total production is used as an acidifier or antioxidant in food and beverage industry to preserve or enhance the flavors and aromas of fruit juices, ice cream, and marmalades (Lancini 2008). Aspergillus sp. and several other yeasts Candida catenula, $C$. guilliermondii, $C$. tropicalis and Yarrowia lipolytica are employed for the production of citric acid (Kubicek 2001). Among microorganisms, two closely related species of the genus Aspergillus, A. niger and $A$. wentii are used for industrial production using metabolic engineering (Max et al. 2010).

Itaconic acid is an important building block in the chemical industry for the production of resins, plastics, paints, and synthetic fibers. It is one of the top 12 building block chemicals and a good substitute for acrylic or methacrylic acid, which are used for the production of plastics (Kawamura et al. 1981; Steiger et al. 2013; Otten et al. 2015). The global market of itaconic acid market was estimated \$126.4 million in 2014 and is expected to grow 
Table 1 Few microbial enzymes with their source and uses

\begin{tabular}{|c|c|c|c|}
\hline Enzymes & Source & Industry & Function \\
\hline Lipase & Aspergillus niger, A. oryzae, A. flavus, Candida Antarctica & $\begin{array}{l}\text { Dairy } \\
\text { Baking } \\
\text { Paper } \\
\text { Polymer } \\
\text { Detergent } \\
\text { Textile } \\
\text { Cosmetics } \\
\text { Leather } \\
\text { Healthcare }\end{array}$ & $\begin{array}{l}\text { Faster cheese ripening, flavor } \\
\text { Dough stability and conditioning } \\
\text { Pitch control } \\
\text { Polymerization of lactones, carbonates } \\
\text { Fat stain elimination } \\
\text { Denim finishing } \\
\text { Skin care } \\
\text { Degreasing } \\
\text { Digestive disorder }\end{array}$ \\
\hline Protease & $\begin{array}{l}\text { Aspergillus niger, A. flavus, B. subtilis, Pseudomonas sp., } \\
\quad \text { Serraita sp., Streptomyces sp. }\end{array}$ & $\begin{array}{l}\text { Cosmetics } \\
\text { Leather } \\
\text { Textile } \\
\text { Paper } \\
\text { Beverages }\end{array}$ & $\begin{array}{l}\text { Removal of dead skin } \\
\text { Dehairing, bathing, soaking } \\
\text { Protein stain removal } \\
\text { Biofilm removal } \\
\text { Restrict haze formation }\end{array}$ \\
\hline Cellulase & $\begin{array}{l}\text { Aspergillus niger, Penicillin funiculosum, Bacillus sp., } \\
\text { Trichoderma reesei }\end{array}$ & $\begin{array}{l}\text { Textile } \\
\text { Detergents } \\
\text { Paper }\end{array}$ & $\begin{array}{l}\text { Cotton softening, denim finishing } \\
\text { Colour clarification } \\
\text { Deinking, drainage improvement }\end{array}$ \\
\hline Amylase & $\begin{array}{l}\text { Aspergillus sp., Bacillus subtilis, B. licheniformi, } \\
\quad \text { B. amyloilquifaciens, Streptomyces sp., }\end{array}$ & $\begin{array}{l}\text { Beverages } \\
\text { Baking } \\
\text { Paper } \\
\text { Textile } \\
\text { Feed } \\
\text { Detergents } \\
\text { Leather } \\
\text { Healthcare }\end{array}$ & $\begin{array}{l}\text { starch hydrolysis } \\
\text { Flour adjustment, bread softness } \\
\text { Deinking, drainage improvement } \\
\text { Desizing } \\
\text { Treatment of barley for poultry and calf } \\
\text { Starch stain removal } \\
\text { fiber splitting } \\
\text { Digestive disorder }\end{array}$ \\
\hline Laccase & Bacillus subtilis, Pseudomonas aeruginosa & $\begin{array}{l}\text { Textile } \\
\text { Cosmetics } \\
\text { Polymer } \\
\text { Paper } \\
\text { Healthcare }\end{array}$ & $\begin{array}{l}\text { Non-chlorine Bleaching, fabric dyeing } \\
\text { Hair dye } \\
\text { Polymerization of bisphenol A } \\
\text { Non-chlorine bleaching, delignification } \\
\text { Detoxification }\end{array}$ \\
\hline
\end{tabular}

at a CAGR of $5.5 \%$ between 2015 and 2023. The high demand for itaconic acid is in the manufacturing of superabsorbent polymers (SAP), which are used in diapers, adult incontinence and feminine hygiene products (Itaconic Acid Market 2015). It also finds large application in food packaging, paints and coatings, emulsifiers, pharmaceuticals, detergents, agriculture, herbicides and printing chemicals (Itaconic Acid Market 2015). Several microorganisms such as Ustilago, Candida, and Rhodotorula are capable of producing itaconic acid, but only Aspergillus terreus is preferred in commercial production of itaconic acid due to high yield up to $80 \mathrm{~g} / \mathrm{L}$ (Tabuchi et al. 1981; Willke and Vorlop 2001; Okabe et al. 2009; Steiger et al. 2013).

Lactic acid is utilized extensively in food and beverages, polymer, pharmaceutical, personal care products, and other industries. The poly lactic acid polymer is biodegradable and biocompatible, and used in pharmaceutical industry for the synthesis of prosthetic devices, sutures and internal drug dosing (San-Martin et al. 1992; Chahal and Starr 2006). The poly lactic acid has several applications in packaging, agriculture, automobile, healthcare, electronics, textile, and other industries (Ghaffar et al. 2014; Singhvi et al. 2010; Martinez et al. 2013). The global lactic acid market is expected to reach $\$ 3.8$ billion by 2020 at a CAGR of $18.6 \%$ from 2015 to 2020 , whereas the global polylactic acid market is estimated to reach nearly $\$ 5.16$ billion by 2020, growing at a CAGR of $20.9 \%$ for the same period (Lactic Acid Market 2015). L (+) lactic acid is produced commercially through fermentation using lactic acid bacteria (Lactobacillus sp.) or fungi (Rhizopus oryzae) in submerged culture. Lactic acid producing bacteria are preferred over fungi as the yield of lactic acid is very high through bacterial mediated fermentations. Stereochemically pure L-(+)-lactic acid is solely produced by Rhizopus oryzae (Martinez et al. 2013). The global chief 
manufacturers of lactic acid are BASF SE (Germany), CSM N.V. (The Netherlands), The Dow Chemical Company (U.S.), Teijin Ltd. (Japan), and Nature Works LLC (U.S) (Lactic Acid Market 2015).

The global market for acetic acid is estimated approximately $\$ 9.0$ billion and expected to reach nearly $\$ 12$ billion by 2022 at a CAGR of $6.8 \%$ from 2015 to 2022 (Acetic Acid Market 2016). Acetic acid is used in the synthesis of other chemical commodities, such as acetic anhydride, vinyl acetate monomer, acetate esters and purified terephthalic acid. These chemicals are further used in wide range of industries such as textiles, construction, automobile, pesticides and food ingredients among others. Vinyl acetate monomer, used in adhesive and sealant industry, was accounted for highest $(\sim 33 \%)$ consumption of the global acetic acid followed by ester solvents in 2014. A variety of bacteria such as Acetobacter, Gluconacetobacter, and Gluconobacter are used for commercial production (Deppenmeier et al. 2002; Demain 2007). In 2014, the acetic acid production amounted to 12 million tons and is expected to reach a volume of nearly 17 million tons by 2022 at a CAGR of $4.7 \%$ during the forecast period (Acetic acid market 2016).

Besides, microorganisms are also used commercially for the fermentative production of gluconic acid by Aspergillus niger and Aureobasidium pullulans, succinic acid by Acctinobacillus succinogenes and pyruvic acid by Torulopsis glabrata (Zeikus et al.1999; Li et al. 2001; Znad et al. 2004; Anastassiadis et al. 2005; Demain 2007). Major manufacturers in organic acids market are Bioamber, Genometica, GSM cargil and Dow Chemicals.

\section{Alchohol}

Ethanol is a primary metabolite and widely used as biofuel. It is also used as a chemical feedstock for many chemical industries, such as solvent for dyes, oils, waxes, explosives, cosmetics, laboratories and as a disinfectant. According to Renewable Fuels Association (2015), approximately 97.0 billion liters of ethanol was produced worldwide in 2015 , and the USA was the largest producer of bioethanol ( $~ 56$ billion liters), followed by Brazil ( $\sim 26$ billion liters). It is reported that annually over $98 \%$ of bioethanol is made from corn. The maximum proportion of total ethanol $(\sim 90$ to $95 \%$ ) is produced using microbial fermentation technology (Sarris and Papanikolaou 2016). Recombinant microorganisms, such as E. coli, Klebsiella oxytoca and Clostridium thermocellum are involved in fermentative production of ethanol using different carbon sources (Moniruzzaman and Ingram 1998; Demain et al. 2005). Genetically engineered microbial strain represent $>95 \%$ ethanol as a fermentation products, whereas wild type E. coli produce a mixture of acids (Demain 2007).
Global glycerol market was estimated $\$ 1.64$ billion in 2014 and is expected to reach nearly $\$ 3$ billion by 2022 at a growth rate of $7.9 \%$. Global glycerol market size was estimated 2443.9 tons in 2014 and is expected to witness annual gains at over 6.5\% from 2015 to 2022 (Glycerol Market Size 2015). Glycerol is used for different applications in foods and beverages, polyether polyols, personal care and pharmaceuticals, alkyd resins, and tobacco humectants. An osmotolerant yeast, Candida glycerinogenes has been reported for microbial production of glycerol $\sim 130 \mathrm{~g} / \mathrm{L}$ with a yield of $>60 \%$ and productivity of $>30 \mathrm{~g} / \mathrm{L}$ day (Wang and Zhuge 1999; Wang et al. 2001).

\section{Antibiotics}

The antibiotic period began in 1929 with the discovery of penicillin from a fungal sp. Penicillin notatum and its commercial production flourished in the 1940s (Demain and Fang 2000). Later, a number of antibiotics have been discovered specifically from fungi and actinomycetes in quest of more effective pharmacological properties and to combat new pathogens. Continuing research in this area led to the discovery of a series of antibiotics, such as cephalosporin, tetracycline, macrolids, ansamacrolids, aminoglycosides, chloramphenicol, glycopeptides, peptide inhibitors, anthracyclins and antifungal antibiotics (Kieslich 1986; Hassan et al. 2012). Nowadays, antibiotics are used for a wide range of applications, such as in chemotherapy, veterinary, plant pathology, food preservation and in research laboratories. These compounds inhibit several pathways, such as nucleic acid synthesis, protein synthesis, cell wall formation, and electron transport pathway (Demain 2007). Some of the microbial species have been reported for their efficient ability to produce a variety of antibiotics. The actinomycetes are responsible for the production of largest proportion $(\sim 75 \%)$ of antibiotics and the Streptomycetes are the largest producer of antibiotics (Omura 1992; Miyadoh 1993; Zedan 1993; Lazzarini et al. 2000; Berdy 2005). Besides, Streptomycetes are also involved in the potential production of a range of pharmaceutical agents including antiparasitic, anticancer, immunosuppressive and enzyme inhibitors. Antibiotics can be classified in different ways, such as based on their chemical structure, biosynthesis pathway, source, mode of action, route of administration, and their effective range. Tetracyclines, the most extensively used broad-spectrum antibiotics, are used considerably in the treatment of diseases caused by a wide range of microorganism including gram-positive and gram-negative bacteria, protozoan parasites, chlamydiae, rickettsiae and mycoplasma (Chopra and Roberts 2001). Ciprofloxacin, another broad-spectrum antibiotic, is effective in the 
treatment of urinary tract infections, chancroid, gastrointestinal infection, skin and bone infections and gonorrhea (Davis et al. 1996).

Cephalosporins have a broader spectrum effect against infections and are less likely to be associated with anaphylactic reactions as compared to penicillin (Bhattacharya 2010). Antibiotics market shared around $4.5 \%$ of the global pharmaceutical market. The global market of systemic antibiotics was nearly $\$ 40.6$ billion in 2015 and is expected to reach about $\$ 44.7$ billion in 2020 at a compound annual growth rate (CAGR) of $2.0 \%$ from 2015 to 2020 (Antibiotics 2016).

The global consumption of antibiotic in 2010 was reported highest in India with 13 billion standard units followed by China (10 billion SU) and USA ( 7 billion SU). The total antibiotic consumption during 2000-2010 was grown by about $35 \%$ from 54,000 to 73,500 million standard units. Meanwhile, the consumption of the most common first-line antibiotics penicillin and cephalosporins were increased by $41 \%$ and accounted for nearly $60 \%$ of total consumption (Van Boeckel et al. 2014; Gelband et al. 2015).

Consumption of two last resort antibiotics carbapenems and polymixins were also increased by approximately 40 and $13 \%$ respectively. Carbapenems are used against most difficult Gram-negative infections while polymixins are used to treat multi-drug resistant infections, such as carbapenem-resistant Enterobacteriaceae. Besides, significant increases were also observed for monobactams (>2000\%), glycopeptides $(>230 \%)$, cephalosporins $(>90 \%)$, and fluoroquinolones $(>60 \%)$ for the same period. At present, consumption of antibiotics in poultry, swine, and cattle to treat infections and to accelerate animal growth is higher than used for the entire human therapeutic purposes. Worldwide, antibiotics consumptions by livestock was estimated 63,200 tons in 2010 and accounted for nearly $67 \%$ of the total antibiotics produced (Pagel and Gautier 2012; Bbosa and Mwebaza 2013; Laxminarayan et al. 2013; Laxminarayan 2014; van Boeckel et al. 2014; Gelband et al. 2015; van Boeckel et al. 2015).

Antibiotics are amongst most frequently prescribed medicine used in healthcare as life saving drugs and hence should be used carefully in treating infections. However, unnecessary and incorrect dosing of antibiotics without proper prescription is the most important factor for antibiotic resistance worldwide. Continuously increasing drug resistance can be prevented through immunization, hand washing, safe food preparation and using antibiotics through proper prescription only when necessary (http:// www.cdc.gov/drugresistance/about.html).

Currently, the key manufacturers in the global antibiotics market are Pfizer Inc., Merck and Co., Eli Lilly and Co., Cubist pharmaceuticals, Johnson \& Johnson from
USA; AstraZeneca and GlaxoSmithKline PLC from UK, and Sanofi-Aventis from France (Antibiotics 2016).

\section{Antitumor agents}

Tumors are generally treated by surgical removal, radiation and chemotherapy. Surgical methods and radiation therapy are inefficient to treat metastatic cancer and therefore, chemotherapy is predominantly helpful in treatment of cancer that has spread to other parts of the body than origin site. According to World Health Organization (WHO), approximately 8.2 million people die annually from cancer, an estimated $13 \%$ of all deaths worldwide, and are expected to increase by $\sim 70 \%$ new cases of cancer over the next two decades (http://www.who.int/cancer/en/). Many microbial metabolites have been reported for effective anticancer properties in healthcare after the discovery of first anticancer agent, actinomycin by Wakesman and Woodruff. Approximately, 60\% of the compounds with anticancer properties are derived from natural sources (Demain and Sánchez 2009). Few microbial products with antineoplastic activities have been illustrated in Table 2. Many of the chemotherapeutic agents used in cancer treatment are secondary metabolites produced by microorganisms, especially of the genus Streptomyces (Demain and Vaishnav 2011; Manivasagan et al. 2014).

The chemotherapy market is currently the fastest growing in the pharmaceutical industry, driven by the magnitude of the disease worldwide and growing understanding of potential therapeutic targets revealed by the molecular genetics assessments of cancer biology.

\section{Other therapeutic agents}

Apart from antibacterial and antitumor agents, other valuable compounds including enzyme inhibitors, immunosuppresants, and alkaloids are of pharmacological importance and also produced by microorganisms.

Immunosuppressant drugs are required to reduce the efficacy of the immune system to prevent rejection of organ transplants and to restrict autoimmune diseases. A number of compounds of microbial origin have been reported for their significant role in suppression of immune response in organ transplant field. Important microbial metabolites, such as cyclosporine A from Tolypcladium nivenum, sirolimus from Streptomyces hygroscopicus, tacrolimus from $S$. tsukubaenis, mycophenolate mofetil from Penicillium stoloniferum and, gliotoxin from Aspergillus and trichoderma have been reported for their immunosuppressive activities and an effective role in organ transplants (Vezina et al. 1975; 
Table 2 Anticancer agents from microorganisms

\begin{tabular}{|c|c|c|c|}
\hline Anticancer agent & Source & Type of cancer & Function \\
\hline Aclacinomycin & Streptomyces galilaeus & Lung cancer & $\begin{array}{l}\text { Inhibition of nucleic acids and protein } \\
\text { synthesis }\end{array}$ \\
\hline Calicheamicin & Micromonospora echinospora & Acute myelogenous leukemia & Cleavage of DNA \\
\hline Adriamycin (doxorubicin) & Streptomyces peucetius & Uterus and ovarian cancer & Inhibition of DNA replication \\
\hline $\begin{array}{l}\text { Chromomycin } \mathrm{A}_{3} \\
\text { (toyamycin and } \\
\text { aburamycin) }\end{array}$ & Streptomyces griseus & Breast and urinary bladder cancer & Inhibition of RNA synthesis \\
\hline Actinomycin D & Streptomyces antibioticus & Wilm's tumor in children & Inhibition of RNA synthesis \\
\hline Taxol (paclitaxel) & $\begin{array}{l}\text { Taxomyces andreanae, } \\
\quad \text { Nodulisporium sylviforme }\end{array}$ & Breast cancer, Kaposi sarcoma & Microtubule depolymerization \\
\hline Mitomycin C & Streptomyces caespitosus & Breast, stomach, oesophagus, bladder & Inhibition of DNA replication \\
\hline Mithramycin & $\begin{array}{l}\text { Streptomyces plicatus, } S . \\
\quad \text { argillaceus, } S . \\
\quad \text { atroolivaceus }\end{array}$ & Bone and testicular tumour & $\begin{array}{l}\text { Inhibition of of RNA synthesis, mRNA } \\
\text { expression and protein synthesis }\end{array}$ \\
\hline Daunomycin & Streptomyces peucetius & $\begin{array}{l}\text { Acute myeloid leukemia, acute } \\
\text { lymphocytic leukemia, Neuroblastoma }\end{array}$ & Inhibition of DNA replication \\
\hline Bleomycin & Streptomyces verticillus & $\begin{array}{l}\text { Hodgkin's disease, squamous cell } \\
\text { carcinoma, testicular cancer, } \\
\text { pleurodesis }\end{array}$ & Cleavage of DNA \\
\hline Neocarzinostatin & Streptomyces carzinostaticus & Liver cancer & $\begin{array}{l}\text { Proteolysis of histone, degradation of } \\
\text { DNA }\end{array}$ \\
\hline Thiocoraline & Micromonospora marina & Colon cancer & Inhibition of DNA replication \\
\hline Alteramide & Alteromonas sp. & $\begin{array}{l}\text { Leukemia, lymphoma, epidermal } \\
\text { carcinoma }\end{array}$ & DNA fragmentation \\
\hline Epothilone & Sorangium cellulosum & Breast cancer & Microtubule depolymerization \\
\hline $\begin{array}{l}\text { Pentostatin } \\
\quad \text { (deoxycoformycin) }\end{array}$ & Streptomyces antibioticus & $\begin{array}{l}\text { Hairy cell leukemia, acute lymphocytic } \\
\text { leukemia, prolymphocytic leukemia }\end{array}$ & Inhibition of DNA \\
\hline Streptozotocin & Streptomyces achromogenes & Pancreatic islet cell cancer & Inhibition of DNA \\
\hline
\end{tabular}

Borel et al. 1976; Kino et al. 1987; Demain 2007). In addition, the analogs of rapamycin, such as everolimus (RAD001), tensirolimus (CCI-799) and ARIAD (AP23573) have been developed for their use in heart transplantation and possible role in the treatment of different types of cancer (Demain and Sánchez 2009).

Enzyme inhibitors have received increasing attention for their potential utilization in medicine and agriculture. A number of enzyme inhibitors for different industrial applications have been isolated from microorganisms. Amylase inhibitors (starch blockers) prevent absorption of dietary starches by the body and are useful to control and treatment of carbohydrate dependent diseases, such as diabetes, obesity and hyperlipemia (Jayaraj et al. 2013). In addition, the amylase inhibitors have also been reported for the treatment of rumen acidosis (Banks et al. 2001). Microbial $\alpha$-amylase inhibitors are paim from Streptomyces corchorushii and TAI-A and TAI-B from Streptomyces calvus TM-521 (Song et al. 2014). The clavulanic acid is derived from Streptomyces clavuligerus. It acts as an inhibitor of $\beta$-lactamase and used to overcome antibiotic resistance (Adrio and Demain 2010).
Lipstatin is a pancreatic lipase inhibitor that is produced by Streptomyces toxytricini and it obstructs gastrointestinal absorption of fat and therefore plays an important role in the treatment of obesity and diabetes (Rodgers et al. 2012). Acarbose, a pseudotetrasaccharide, contains valienamine which is used to inhibit intestinal $\alpha$-glucosidase and sucrase. It is produced by Actinoplanes sp. SE 50 and useful to reduce starch breakdown in the intestine, and hence used in the treatment of type 2 diabetes mellitus diabetes in humans (Demain and Sánchez 2009). Protease inhibitors, such as antipain, leupeptin and chymostatin have also find important applications in the treatment of AIDS, hepatitis, pancreatitis and cancer. These protease inhibitors are produced by different species of the genus Streptomyces (Butler 2008). Enzyme inhibitors of fungal origin are also used against various diseases, such as Alzheimer's disease, diabetes, cancer and many more (Paterson 2008).

Alkaloids are heterocyclic organic nitrogen containing compounds that have pharmaceutical values including anticancer and anti-malarial effects and are synthesized from amino acids (ornithine, lysine, aspartic acid, 
phenylalanine, tyrosine and tryptophan) by microorganisms, plants and some animals (Marienhagen and Bott 2013; Wang et al. 2016). For example, nicotine is derived from ornithine whereas ephedrine and morphine are derived from phenylalanine and tyrosine, respectively. The ergot alkaloids were originally derived from ergot, a sclerotium (twisted mat of fungal hyphae). Most of these alkaloids are derived from the Claviceps sclerotium. Besides, the alkaloids have also been reported by other fungi including Aspergillus, Penicillium, and Rhizopus. The naturally occurring ergot alkaloids can be divided into lysergic acid derivatives and clavine alkaloids. Ergot alkaloids have been utilized for various diseases, for example ergometrine, ergonovine, and ergotamine for inducing labor in mid-wifery, stopping bleeding after birth, and blocking the sympathetic system for treating migraines, respectively. In addition, the diethylamide derivate of lysergic acid is a powerful hallucinogenic drug for experimental psychotherapy and dihydro derivates of clavinet alkaloid used as strong stimulants of oxytoxic (milk secreting) activity or of uterine contractions. Semisynthetic ergot alkaloids have other major applications as potential therapeutic agents, for example, nigericoline is used in peripheral and cerebral circulation disorder treatment and Lysenyl treats hypertension and migraine. Some other ergot alkaloids have also been reported as pharmaceutical drugs for treatment of prostrate cancer, Parkinson's disease and lack of milk production after child birth (Schiff 2006; Okafor 2007; Gerhards et al. 2014; Mahmood and Mahmood 2015).

Antiparasitic compounds are used to inhibit the growth and reproduction of parasite organisms that live on the body of humans and animals and can cause serious health problems including death of the host. More than 3200 varieties of parasites have been reported so far from protozoa and helminths. According to $\mathrm{WHO}$, approximately $25 \%$ of global population is infected with roundworm (Demain and Sánchez 2009). The significance of antiparasitic drugs can be evaluated by the fact that antiparasitic drug discoverers, Satoshi Omura, William Campbell and Youyou Tu shared the 2015 Novel Prize in Physiology or Medicine for their work on avermectin and artemisinin (World report 2015). Avermectin and its derivatives are extremely effective against river blindness, lymphatic filariasis, and several other parasitic infections while artemisinin is used for most effective treatment for malaria. Omura and coworkers reported eight compounds, which are produced as secondary metabolites by Streptomyces avermitilis and were named avermectins (Stapley 1982) and these compounds possessed activity against nemathelminthes and arthropods. Ivermectins is a semisynthetic derivative of avermectin compounds, which is used to control human onchocerciasis and strongyloidiasis (Shikiya et al. 1992). Another derivative selamectin is highly effective against heartworms and fleas in companion animals (Michael et al. 2002). Actinomycetes produce polyether antibiotics, such as monensin, lasalocid $\mathrm{A}$ and salinomycin, which are used to control poultry coccidiosis (Shiomi and Omura 2004). The application of anticoccidiales has significantly reduced the mortality and production loss caused by coccidiosis in poultry industry (Westley 1977).

\section{Biopesticides and plant growth regulators}

Chemical pesticides, such as halogenated, carbamate and organophosphorus compounds have been used widely for agriculture system. Their use as pest control results in several problems, such as toxic effect on wild life, human and domestic animals; chemical changes on undesired insects/pests on their predators, parasites and contamination of ground water (Lacey and Siegel 2000; Canan 2013; Nawaz et al. 2016). Biopesticides include biofungicides (Trichoderma), bioherbicides (Phytopthora) and bioinsecticides (Bacillus thuringiensis, B. sphaericus) are preferred over conventional pesticides due to biodegradable nature, highly effectiveness, target specificity and less environmental risks (Canan 2013). The global biopesticides market is expected to reach $\$ 6.60$ billion by 2020 at a CAGR of $18.8 \%$ for the period from 2015 to 2020 (Biopesticide market 2015).

Biological pesticides based on pathogenic microorganisms specific to a target pest and pose less threat to the ecosystem. The potential benefits to agriculture and public health programmes through the use of biopesticides are considerable. Over 100 bacteria have been identified as insect pathogens, among them Bacillus thuringiensis (Bt), a gram-positive endospore forming bacteria, has got the maximum importance as an insecticidal bacterium to control caterpillar pests, fly and mosquito larvae, and beetles (Argolo-Filho and Loguercio 2014; Nawaz et al. 2016). Bt produces insecticidal endotoxin protein during spore formation that binds to and destroy the cellular lining of the digestive tract, causing the insect to stop feeding and die (Schunemann et al. 2014). The protein kills mainly caterpillars of the Lepidoptera (butterflies and moths), mosquito larvae, and simuliid blackflies. Bt sprays are used on fruit and vegetable crops, on broad-acre crops such as maize, soya bean and cotton (Meadows 1993).

Various subspecies of $\mathrm{Bt}$ are used for their different function as bioinsectisides, such as to control beetle larvae (var. tenebrionis), caterpillars (var. kurstaki, entomocidus, galleriae and aizawai), and mosquito and blackfly larvae (var. israeliensis) (Lambert et al. 1992; Milner 1994). Bacillus sphaericus is another insecticidal bacterium that 
has been used to control mosquito species. Certain strains of Bacillus subtilis, B. pumilus, Pseudomonas fluorescens, $P$. aureofaciens and Streptomyces spp. prevent plant diseases by outcompeting plant pathogens in the rhizosphere, producing anti-fungal compounds and promoting plant and root growth. They are used against a range of plant pathogens including damping-off and soft rots (Canan 2013; Chatzipavlidis et al. 2013).

Biofungicides have been used in both the phylloplane and rhizosphere to control plant diseases caused by fungi, bacteria or nematodes including some insect pests and weeds. The most common commercial fungal bio-pesticides used in agricluture and forestry are Trichoderma spp. and Beauveria bassiana. Trichoderma harzianum is an antagonist of Rhizoctionia, Pythium, Fusarium and other soil-borne pathogens. Beauveria bassiana and Metarhizium anisopliae are parasitic fungi found on many insect species. Beauveria bassiana has been proved effective in controlling crop pests such aphids, thrips and whitefly pesticide resistant strains. Metarhizium anisopliae is used against spittlebugs on sugarcane and grassland and furthermore for the control of locust and grasshopper pests in Africa and Australia. Coniothyrium minitans is a mycoparasite applied against Sclerotinia sclerotiorum (Chandler et al. 2011; Chatzipavlidis et al. 2013).

Herbicides are widely used in agriculture, industry and urban areas for weed management. With increasing global environmental consciousness, bioherbicides are proved highly effective for weed control in eco-friendly manner. Microbial herbicides can be divided into microbial preparations (microorganisms that control weeds) and microbial derived herbicides. Products based on Colletotrichum spp and Phytophthora are used commercially against agricultural weeds (Demain and Sánchez 2009; Chandler et al. 2011). The global bioherbicides market was around $\$ 973$ million in 2015 and is expected to grow at a CAGR of $10.87 \%$ for the period from 2015 to 2020 . The driving factors for the growth of the market are the ecofriendly nature of bioherbicides, increasing public awareness and lesser development of pest resistance (Global Bioherbicides Market 2016). Research and development in the field of biopesticide applications greatly reduce the environmental pollution caused by the chemical synthetic insecticides and promotes sustainable development of agriculture. Pesticides are employed in modern agriculture to control pests and to increase crop yield.

Plant growth regulators, also called plant hormones are chemical compounds that act as messengers to regulate growth of plants and differentiation of plant cells. There are currently five groups of plant hormones: auxins, gibberellins, cytokinins, abscisic acid and ethylene. These plant hormones work together to regulate the growth and development of cells (Spence and Bais
2015). The plant growth regulators market was estimated to be valued at $\$ 1.6$ billion in 2015 and is projected to grow at a CAGR of $3.6 \%$ from 2015 to 2020 to reach an expected value of $\$ 1.91$ billion by 2020 (Plant Growth Regulators 2015). Among the types of plant growth regulators, gibberellins accounted for the largest market share followed by cytokinins and auxins. Gibberellins are used on a large scale for extensive production and cultivation of fruits and vegetables and it is mainly involved in early embryo growth, seed germination, stem elongation and flowering. The worldwide consumption of gibberellic acid is approximately 60 tons annually. A number of microorganisms are utilized to produce these hormones (MacMillan 2001; Yurekli et al. 1999; Karadeniz et al. 2006; Tsavkelova et al. 2006). The global leading manufacturers of plant hormones are FMC Corporation and The Dow Chemical Company from USA, Syngenta AG (Switzerland), BASF SE (Germany) and Nufarm Limited (Australia) (Plant Growth Regulators 2015).

\section{Conclusion}

Microorganisms, primary source of nutrients, are essential to all life forms and are efficiently involved in healthcare, agriculture and nutrition. These tiny entities are involved in the preparation of variety of foods and also used as feed supplements. Microorganisms produce antibiotics, antitumor agents, immunosuppressants, alkaloids, and enzyme inhibitors, which are used in the treatment of infectious as well as fatal diseases worldwide and play a key role in reduced mortality rate and better human life expectancy. Application of enzymes has been increasing continuously as microbial enzymes have significant potential for many industries, including pharmaceuticals, food, feed, beverages, detergents, leather processing and paper and pulp to meet demand of rapidly growing population. Pesticides and growth regulators of microbial origin have proved their significant potential in sustainable agriculture development and consequently in the development of green environment.

Open Access This article is distributed under the terms of the Creative Commons Attribution 4.0 International License (http:// creativecommons.org/licenses/by/4.0/), which permits unrestricted use, distribution, and reproduction in any medium, provided you give appropriate credit to the original author(s) and the source, provide a link to the Creative Commons license, and indicate if changes were made.

\section{References}

Acetic Acid Market (2016) Acetic acid market-growth, share, opportunities \& competitive analysis, 2015-2022. http://www. 
credenceresearch.com/report/acetic-acid-market. Accessed on 25 Apr 2016

Adrio JL, Demain AL (2010) Recombinant organisms for production of industrial products. Bioeng Bugs 1(2):116-131. doi:10.4161/ bbug.1.2.10484

Adrio JL, Demain AL (2014) Microbial enzymes: tools for biotechnological processes. Biomolecules 4:117-139

Amino Acids Market (2015) Amino Acids market size \& research report, 2022. Radiant Insights Inc. http://www.radiantinsights. com/research/amino-acids-market. Accessed 26 Apr 2016

Anastassiadis S, Aivasidis A, Wandrey C, Rehm HJ (2005) Process optimization of continuous gluconic acid fermentation by isolated yeast-like strains of Aureobasidium pullulans. Biotechnol Bioeng 91:494-501

Anbu P, Gopinath SC, Chaulagain BP et al (2015) Microbial enzymes and their applications in industries and medicine 2014. Biomed Res Int 2015:1-3

Antibiotics (2016) Antibiotics: technologies and global markets (PHM025D). BCC Research. Accessed 24 Apr 2016

Argolo-Filho RC, Loguercio LL (2014) Bacillus thuringiensis is an environmental pathogen and host-specificity has developed as an adaptation to human-generated ecological niches. Insects 5(1):62-91. doi:10.3390/insects5010062

Banks BJ, Haxell MA, Lunn G, Pacey MS, Roberts LR (2001) Treatment of rumen acidosis with alpha-amylase inhibitors. European Patent EP1157696 A2

Barker DF, Campbell AM (1981) Genetic and biochemical characterization of the birA gene and its product: evidence for a direct role of biotin holoenzyme synthetase in repression of the biotin operon in Escherichia coli. J Mol Biol 146:469-492

Bbosa GS, Mwebaza N (2013) Global irrational antibiotics/antibacterial drugs use: a current and future health and environmental consequences. In: Mendez-Vilas A (ed) Microbial pathogens and strategies for combating them: science, technology and education. Formatex, Badajoz

Becker J, Wittmann C (2012) Systems and synthetic metabolic engineering for amino acid production-the heartbeat of industrial strain development. Curr Opin Biotechnol 23:718-726

Bentley R (1997) Microbial secondary metabolites play important roles in medicine; prospects for discovery of new drugs. Perspect Biol Med 40:364-394

Berdy J (2005) Bioactive microbial metabolites a personal view. J Antibiot 58(1):1-26

Berg JM, Tymoczko JL, Stryer L (2002) Biochemistry, 5th edn. Section 8.6, Vitamins Are Often Precursors to Coenzymes. W H Freeman, New York. http://www.ncbi.nlm.nih.gov/books/ NBK22549/

Bhalla TC, Sharma NN, Sharma M (2007) Production of metabolites, industrial enzymes, amino acids, organic acids, antibiotics, vitamins and single cell proteins. National Science Digital Library, India

Bhattacharya S (2010) The facts about penicillin allergy: a review. J Adv Pharm Technol Res 1(1):11-17

Biopesticides Market (2015) Biopesticides market by type (bioinsecticides, biofungicides, bioherbicides, and bionematicides), origin (beneficial insects, microbials, and biochemical), mode of application, formulation, crop type \& region-global forecast to 2020. Accessed 25 Apr 2016

Bisen PS, Debnath M, Prasad GB (2012) Microbes: concepts and applications. Wiley-Blackwell. ISBN 9781118311899

Bolander FF (2006) Vitamins: not just for enzymes. Curr Opin Investig Drugs 7(10):912-915

Bommarius AS, Schwarm M, Drauz K (1998) Biocatalysis to amino acid-based chiral pharmaceuticals-examples and perspectives. J Mol Catal B Enzym 5(1-4):1-11
Borel JF, Feurer C, Gabler HU, Stahelin H (1976) Biological effects of cyclosporin A: a new antilymphocytic agent. Agents Actions 6:468-475

Butler MS (2008) Natural products to drugs: natural product derived compounds in clinical trials. Nat Prod Rep 25(3):475-516

Canan U (2013) Microorganisms in biological pest control-a review (bacterial toxin application and effect of environmental factors), current progress in biological research, Dr. Marina Silva-Opps (Ed.). InTech. doi:10.5772/55786

Carboxylic Acids Market (2015) carboxylic acids (acetic, valeric, isovaleric, formic, propionic, butyric, isobutyric, citric, caproic, stearic, and others) market for food \& beverages, animal feed, pharmaceuticals, personal care \& cosmetics, consumer goods, lubricants, and other end-users-global industry analysis, size, share, growth, trends and forecast 2015-2023. Accessed 23 Apr 2016

Chahal SP, Starr JN (2006) Lactic acid. Ullmann's Encycl Ind Chem. doi:10.1002/14356007.a15_097.pub2

Chandler D, Bailey AS, Tatchell GM et al (2011) The development, regulation and use of biopesticides for integrated pest management. Philos Trans R Soc B Biol Sci 366:1987-1998

Chatzipavlidis I, Kefalogianni L, Venieraki A, Holzapfel W (2013) Status and trends of the conservation and sustainable use of microorganisms in agroindustrial processes. http://www.fao.org/ docrep/meeting/028/mg339e.pdf

Choi JM, Han SS, Kim HS (2015) Industrial applications of enzyme biocatalysis: current status and future aspect. Biotechnol Adv 33:1443-1454

Chopra I, Roberts M (2001) Tetracycline antibiotics: mode of action, applications, molecular biology and epidemiology of bacterial resistance. Microbiol Mol Biol Rev 65(2):232-260

Citric Acid Market (2015) Citric acid market by form (anhydrous and liquid), application (food, pharmaceuticals, and cosmetics), function (acidulant, antioxidant, preservative, and sequestrant), and by region (North America, Europe, Asia-Pacific, and RoW)-Global Forecast to 2020. Accessed 2 May 2016

Davis R, Markham A, Balfour JA (1996) Ciprofloxacin: an updated review of its pharmacology, therapeutic efficacy and tolerability. Drugs 51(6):1019-1074

Demain AL (1999) Pharmaceutically active secondary metabolites of microorganisms. Appl Microbiol Biotechnol 52:455-463

Demain AL (2007) The business of biotechnology. Ind Biotechnol 3:269-283

Demain AL, Fang A (2000) The natural functions of secondary metabolites. Adv Biochem Eng Biotechnol 69(1):1-39

Demain AL, Sánchez S (2009) Microbial drug discovery: 80 years of progress. J Antibiot 62:5-16

Demain AL, Vaishnav P (2011) Natural products for cancer chemotherapy. Microb Biotechnol 4(6):687-699

Demain AL, Newcomb M, Wu JHD (2005) Cellulase, clostridia and ethanol. Microbiol Mol Biol Rev 69:124-154

Deppenmeier U, Hoffmeister M, Prust C (2002) Biochemistry and biotechnological applications of Gluconobacter strains. Appl Microbiol Biotechnol 60:233-242

Gelband H et al (2015) The state of the world's antibiotics 2015. Center for Disease Dynamics, Economics \& Policy CDDEP, Washington DC

Gerhards N, Neubauer L, Tudzynski P, Li SM (2014) Biosynthetic pathways of ergot alkaloids. Toxins 6:3281-3295. doi:10.3390/ toxins6123281

Ghaffar T, Irshad M, Anwar Z (2014) Recent trends in lactic acid biotechnology: a brief review on production to purification. J Radiat Res Appl Sci 7:222-229

Global Bioherbicides (2016) Global Bioherbicides market-growth, trends and forecast 2015-2020. http://www.researchandmarkets. com/research/5nslm5/global. Accessed 12 May 2016 
Glycerol Market Size (2015) Glycerol market size, price trend, research report 2022. Radiant Insights Inc. http://www. radiantinsights.com/research/glycerol-market. Accessed 12 May 2016

Gupta UC, Gupta SC (2015) Role of vitamins in human health and nutrition: sources and morbidity. Curr Nutr Food Sci 11(2):105-115. doi:10.2174/1573401311666150429225548

Gurung N, Ray S, Bose S, Rai V (2013) A broader view: microbial enzymes and their relevance in industries, medicine, and beyond. BioMed Res Int. doi:10.1155/2013/329121

Hartmann M, Tauch A, Eggeling L (2003) Identification and characterization of the last two unknown genes, dapC and dapF, in the succinylase branch of the L-lysine biosynthesis of Corynebacterium glutamicum. J Biotechnol 104:199-211

Hassan M, Kjos M, Nes IF et al (2012) Natural antimicrobial peptides from bacteria: characteristics and potential applications to fight against antibiotic resistance. J Appl Microbiol 113(4):723-736. doi:10.1111/j.1365-2672.2012.05338.x (Epub 2012 Jun 8)

Ikeda M (2003) Amino acid production processes. Adv Biochem Eng Biotechnol 79:1-35

Imshenetsky AA, Lysenko SV, Kazakov GA (1978) Upper boundary of the biosphere. Appl Environ Microbiol 35:1-5

Industrial Enzymes Market (2015) Industrial enzymes market by type (carbohydrases, proteases, non-starch polysaccharides \& others), application (food \& beverage, cleaning agents, animal feed \& others), brands \& by region- global trends and forecasts to 2020 . http://www.marketsandmarkets.com/Market-Reports/industrialenzymes-market-237327836.html. Accessed on 24 Mar 2016

Itaconic Acid Market (2015) Itaconic acid market-global industry analysis, size, share, growth, trends and forecast 2015-2023. Globe Newswire, Albany. Accessed 24 Apr 2016

Ivanov K, Ivanova S, Georgieva M, Atanasov P (2014) Production and regulatory analytical control of amino acids include in food additives. Pharmacia 61(2):48-54

Jayaraj S, Suresh S, Kadeppagari RK (2013) Amylase inhibitors and their biomedical applications. Starch Stärke 65(7-8):535-542

Kamini NR, Hemchander C, Geraldine J et al (1999) Microbial enzyme technology as an alternative to conventional chemical in leather industry. Curr Sci 76:101

Karadeniz A, Topcuoğlu SF, İnan S (2006) Auxin, gibberellin, cytokinin and abscisic acid production in some bacteria. World J Microbiol Biotechnol 22(10):1061-1064

Kawamura D, Furuhashi M, Saito O, Matsui H (1981) Production of itaconic acid by fermentation. Shizuoka Prefecture; Iwata Kagaku Kogyo Japan Patent 56137893

Kieslich K (1986) Production of drugs by microbial biosynthesis and biotransformation: possibilities, limits and future developments. 1st Communication. Arzneimittelforschung 36(4):774-778

Kino T, Hatanaka H, Hashimoto M et al (1987) FK-506, a novel immunosuppressant isolated from Streptomyces. 1: fermentation, isolation and physico-chemical and biological characteristics. J Antibiot 40:1249-1255

Kubicek CP (2001) Organic acids. In: Ratledge C, Kristiansen B (eds) Basic biotechnology, vol 2. Cambridge University Press, Cambridge, pp 305-324

Kusel JP, Fa YH, Demain AL (1984) Betaine stimulation of vitamin $\mathrm{B}_{12}$ biosynthesis in Pseudomonas denitrificans may be mediated by an increase in activity of $\delta$-aminolaevulinic acid synthase. J Gen Microbiol 130:835-841

Lacey LA, Siegel JP (2000) Safety and ecotoxicology of entomopathogenic bacteria, in entomopatgenic bacteria: from laboratory to field application. doi:10.1007/978-94-017-1429-7_14

Lactic Acid Market (2015) Lactic acid market by application (biodegradable polymer, food \& beverage, personal care \& pharmaceutical) \& polylactic acid market by application (packaging, agriculture, automobile, electronics, textile), \& by geography—global trends \& forecasts to 2020. Accessed $26 \mathrm{Apr}$ 2016

Lambert B, Hofte H, Annys K, Jansens S, Soetaert P, Peferoen M (1992) Novel Bacillus thuringiensis insecticidal crystal protein with a silent activity against coleopteran larvae. Appl Environ Microbiol 58(8):2536-2542

Lancini G (2008) Parte I-L'uso industriale dei microrganismi. Storia e campi di applicazione. In: Donadio S, Marino G (eds) Biotecnologie Microbiche. Casa Editrice Ambrosiana, Milan, pp 5-35

Laxminarayan R (2014) Antibiotic effectiveness: balancing conservation against innovation. Science 345(6202):1299-1301

Laxminarayan R, Duse A, Wattal C et al (2013) antibiotic resistancethe need for global solutions. Lancet Infect Dis 13(12):1057-1098. doi:10.1016/S1473-3099(13)70318-9

Lazzarini A, Cavaletti L, Toppo G, Marinelli F (2000) Rare genera of actinomycetes as potential producers of new antibiotics. Antonie Van Leeuwenhoek 78(3-4):399-405

Leuchtenberger W, Huthmacher K, Drauz K (2005) Biotechnological production of amino acids and derivatives: current status and prospects. Appl Microbiol Biotechnol 69:1-8

Li Y, Chen J, Lun SY, Rui XS (2001) Efficient pyruvate production by a multi-vitamin auxotroph of Torulopsis glabrata: key role and optimization of vitamin levels. Appl Microbiol Biotechnol 55:680-685

Li S, Yang X, Yang S et al (2012) Technology prospecting on enzymes: application, marketing and engineering. Comput Struct Biotechnol J 2:1-11

Liu L, Haiquan Yang H, H-d Shin (2013) How to achieve high-level expression of microbial enzymes strategies and perspectives. Bioengineered 4(4):212-223

Lysine Market Analysis (2014) Lysine market analysis by application (animal feed, food \& dietary supplements, pharmaceuticals), by livestock (swine, poultry) and segment forecasts to 2020. Published: June 2014. ISBN Code: 978-1-68038-137-5. Accessed 26 Apr 2016

MacMillan J (2001) Occurrence of gibberellins in vascular plants, fungi, and bacteria. J Plant Growth Regul 20:387-442

Mahmood ZA (2015) Microbial amino acids production (chapter: 9): microbial biotechnology, progress and trends. CRC Press, Tayler \& Francis Group, USA. doi:10.13140/2.1.2822.2245

Mahmood ZA, Mahmood SBZ (2015) Microbial healthcare products (chapter: 11): microbial biotechnology, progress and trends. CRC Press, Tayler \& Francis Group, USA. doi:10.13140/2.1. 1511.5040

Manivasagana P, Venkatesana J, Sivakumar K, Kima SK (2014) Pharmaceutically active secondary metabolites of marine actinobacteria. Microbiol Res 169:262-278

Marienhagen J, Bott M (2013) Metabolic engineering of microorganisms for the synthesis of plant natural products. J Biotechnol 163:166-178

Martinez FAC, Balciunas EM, Salgado JM et al (2013) Lactic acid properties, applications and production: a review. Trends Food Sci Technol 30:70-83

Mata-Gomez LC, Montanez JC, Mendez-Zavala A, Aguilar CN (2014) Biotechnological production of carotenoids by yeasts: an overview. Microb Cell Fact 13:12. doi:10.1186/1475-2859-1312

Max B, Salgado JM, Rodríguez N et al (2010) Biotechnological production of citric acid. Braz J Microbiol 41(4):862-875. doi:10.1590/S1517-83822010000400005

Meadows MP (1993) Bacillus thuringiensis in the environmentecology and risk assessment. In: Entwistle PF, Cory JS, Bailey MJ, Higgs S (eds) Bacillus thuringiensis: an environmental biopesticide; theory and practice. Wiley, Chichester, pp 193-220 
Michael B, Meinke PT, Shoop WL (2002) Comparison of ivermectin, doramectin, selamectin, and eleven intermediates in a nematode larval development assay. J Parasitol 87:692-696

Microbial Products (2015) Microbial products: technologies, applications and global markets (September 2015: BIO086C). BCC Research

Milner RJ (1994) History of Bacillus thuringiensis. Agric Ecosyst Environ 49(1):9-13

Miyadoh S (1993) Research on antibiotic screening in japan over the last decade: a producing microorganisms approach. Actinomycetologica 9:100-106

Moniruzzaman M, Ingram LO (1998) Ethanol production from dilute acid hydrolysate of rice hulls using genetically engineered Escherichia coli. Biotechnol Lett 20:943-947

Mueller U, Huebner S (2003) Economic aspects of amino acid production. Adv Biochem Eng Biot 79:137-170

Nawaz M, Mabubu JI, Hua H (2016) Current status and advancement of biopesticides: microbial and botanical pesticides. J Entomol Zool Stud 4(2):241-246

Okabe M, Lies D, Kanamasa S, Park EY (2009) Biotechnological production of itaconic acid and its biosynthesis in Aspergillus terreus. Appl Microbiol Biotechnol 84:597-606

Okafor N (2007) Production of ergot alkaloids. In: modern industrial microbiology and biotechnology. ISBN 978-1-57808-434-0 (HC), ISBN 978-1-57808-513-2 (PB)

Omura S (1992) Trends in the search for bioactive microbial metabolites. J Ind Microbiol 10(3-4):135-156

Otten A, Brocker M, Bott M (2015) Metabolic engineering of Corynebacterium glutamicum for the production of itaconate. Metab Eng 30:156-165. doi:10.1016/j.ymben.2015.06.003

Pagel SW, Gautier P (2012) Use of antimicrobial agents in livestock. Rev Sci Tech 31(1):145-188

Park JH, Lee SY (2008) Towards systems metabolic engineering of microorganisms for amino acid production. Curr Opin Biotechnol 19:454-460

Paterson RRM (2008) Fungal enzyme inhibitors as pharmaceuticals, toxins and scourge of PCR. Curr Enz Inhib 4(1):46-59

Plant Growth Regulators (2015) Plant growth regulators market by type (auxins, cytokinins, and gibberellins), crop type (cereals \& grains, fruits \& vegetables, oilseeds \& pulses, and turfs, ornamentals \& others), \& by region-global trends \& forecast to 2020 (http://marketsandmarkets.com). Accessed 25 Apr 2016

Polen T, Kramer M, Bongaerts J et al (2005) The global gene expression response of Escherichia coli to L-phenylalanine. Biotechnol 115:221-237

Renewable Fuels Association (2015) http://www.ethanolrfa.org/ resources/industry/statistics/\#1454098996479-8715d404-e546. Accessed 3 May 2016

Rodgers RJ, Tschöp MH, Wilding JP (2012) Anti-obesity drugs: past, present and future. Dis Model Mech 5(5):621-626

Sanchez S, Demain AL (2008) Metabolic regulation and overproduction of primary metabolites. Microb Biotechnol 1:283-319

San-Martin M, Pazos C, Coca J (1992) Reactive extraction of lactic acid with alamine 336 in the presence of salts and lactose. J Chem Technol Biotechnol 54:1-6

Sarkissian CN, Shao Z, Blain F et al (1999) A different approach to treatment of phenylketonuria: phenylalanine degradation with recombinant phenylalanine ammonia lyase. Proc Natl Acad Sci USA 96:2339-2344

Sarris D, Papanikolaou S (2016) Biotechnological production of ethanol: biochemistry, processes and technologies. Eng Life Sci 16:307-329. doi:10.1002/elsc.201400199

Sauer M, Porro D, Mattanovich D, Branduardi P (2008) Microbial production of organic acids: expanding the markets. Trends Biotechnol 26(2):100-108. doi:10.1016/j.tibtech.2007.11.006 (Epub 2008 Jan 11)
Schiff PL (2006) Ergot and its alkaloids. Am J Pharm Educ 70(5):98

Schunemann R, Knaak N, Fiuza LM (2014) Mode of action and specificity of Bacillus thuringiensis toxins in the control of caterpillars and stink bugs in soybean culture. ISRN Microbiol 135675:12. doi: $10.1155 / 2014 / 135675$

Shikiya K et al (1992) Efficacy of ivermectin against Strongyloides stercoralis in humans. Intern Med 31:310-312

Shimizu S (2001) Vitamins and related compounds: microbial production. In: Rehm H-J, Reed G (eds) Biotechnology: special processes, vol 10, 2nd edn. Wiley-VCH Verlag GmbH, Weinheim. doi:10.1002/9783527620937.ch11

Shiomi K, Omura S (2004) Antiparasitic agents produced by microorganisms. Proc Jpn Acad Ser B 80(6):245-258. doi:10. 2183/pjab.80.245

Singh R, Kumar M, Mittal A, Mehta PK (2016) Microbial enzymes: industrial progress in 21st century. 3. Biotech 6:174. doi:10. 1007/s13205-016-0485-8

Singhvi M, Joshi D, Adsul M et al (2010) D-(-)-Lactic acid production from cellobiose and cellulose by Lactobacillus lactis mutant RM2-24. Green Chem 12(6):1106-1109

Song MK, Bischoff DS, Uyemura K, Song AM, Yamaguchi DT (2014) Prevention and treatment of obesity and diabetes and their related complications. J Mol Genet Med S 1:009

Spalla C, Grein A, Garofano L, Ferni G (1989) Microbial production of vitamin $\mathrm{B}_{12}$. In: Vandamme EJ (ed). Biotechnology of vitamins, pigments and growth factors. Elsevier Appl Science, New York, pp 257-284. doi:10.1007/978-94-009-1111-6_15

Spence C, Bais H (2015) Role of plant growth regulators as chemical signals in plant-microbe interactions: a double edged sword. Curr Opin Plant Biol 27:52-58. doi:10.1016/j.pbi.2015.05.028

Stapley EO (1982) Avermectins, antiparasitic lactones produced by Streptomyces avermitilis isolated from a soil in Japan. In: Umezawa H, Demain AL, Hata R, Hutchinson CR (eds) Trends in antibiotic research. Japan Antibiotic Research Association, Tokyo, pp 154-170

Steiger MG, Blumhoff ML, Mattanovich D, Sauer M (2013) Biochemistry of microbial itaconic acid production. Front Microbiol 4:1-5

Sun X, Shen X, Jain R et al (2015) Synthesis of chemicals by metabolic engineering of microbes. Chem Soc Rev 44:3760-3785. doi:10.1039/C5CS00159E

Survase SA, Bajaj IB, Singhal RS (2006) Production of vitamins. Food Technol Biotechnol 44(3):381-396

Tabuchi T, Sugisawa T, Ishidor T et al (1981) Itaconic acid fermentation by a yeast belonging to the genus Candida. Agric Biol Chem 45:475-479

Tamano K (2014) Enhancing microbial metabolite and enzyme production: current strategies and challenges. Front Microbiol 5:718

Treem WR, McAdams L, Stanford L et al (1999) Sacrosidase therapy for congenital sucrase-isomaltase deficiency. J Pediatr Gastroenterol Nutr 28:137-142

Tsavkelova EA, Klimova S-Yu, Cherdyntseva TA, Netrusov AI (2006) Hormones and hormone-like substances of microorganisms: a review. Appl Biochem Microbiol 42(3):229-235

Van Boeckel TP, Gandra S, Ashok A et al (2014) Global antibiotic consumption 2000 to 2010: an analysis of national pharmaceutical sales data. Lancet Infect Dis 3099(14):1-9

Van Boeckel TP, Brower C, Gilbert M et al (2015) Global trends in antimicrobial use in food animals. Proc Natl Acad Sci USA 112(18):5649-5654

van Ooyen J, Noack S, Bott M et al (2012) Improved L-lysine production with Corynebacterium glutamicum and systemic insight into citrate synthase flux and activity. Biotechnol Bioeng 109:2070-2081. doi:10.1002/bit.24486 
Vellard M (2003) The enzyme as drug: application of enzymes as pharmaceuticals. Curr Opin Biotechnol 14:444-450

Vezina C, Kudelski A, Sehgal SN (1975) Rapamycin (AY 22,989), a new antifungal antibiotic. 1: taxonomy of the producing streptomycete and isolation of the active principle. J Antibiot 28:721-726

Vitamins (2015) Vitamins: the global strategic business report. The Global Industry Analysts Inc. http://www.strategyr.com/ MarketResearch/Vitamins_Market_Trends.asp. Accessed on 24 Apr 2016

Wainwright M, Alharbi S, Wickramasinghe NC (2006) How do microorganisms reach the stratosphere. Int $\mathrm{J}$ Astrobiol $5(1): 13-15$

Wang ZX, Zhuge J (1999) Cloning a gene encoding cytoplasmic glycerol-3-phosphate dehydrogenase from Candida glycerolgenesis. Acta Microbiol Sin 39:321-326

Wang ZX, Zhuge J, Fang H, Prior BA (2001) Glycerol production by microbial fermentation: a review. Biotechnol Adv 19:201-223

Wang B, Lin L, Lu L, Chen W (2012) Optimization of $\beta$-carotene production by newly isolated Serratia marcescens strain. Electron J Biotechnol. doi:10.2225/vol15-issue6-fulltext-4

Wang J, Guleria S, Koffas MAG, Yan Y (2016) Microbial production of value added nutraceuticals. Curr Opin Biotechnol 37:97-104
Wendisch VF (2014) Microbial production of amino acids and derived chemicals: synthetic biology approaches to strain development. Curr Opin Biotechnol 30:51-58. doi:10.1016/j. copbio.2014.05.004

Westley JW (1977) Polyether antibiotics: versatile carboxylic acid ionophores produced by Streptomyces. Adv Appl Microbiol 22:177-223

Willke T, Vorlop KD (2001) Biotechnological production of itaconic acid. Appl Microbiol Biotechnol 56:289-295

World report (2015) World report: 2015 Nobel Prize goes to antiparasitic drug discoverers. http://www.thelancet.com

Yurekli F, Yesilada O, Yurekli M, Topcuoglu SF (1999) Plant growth hormone production from olive oil mill and alcohol factory wastewaters by white rot fungi. World J Microbiol Biotechnol 15:503-505

Zedan $H$ (1993) The economic value of microbial diversity. Biotechnology 43:178-185

Zeikus JG, Jain MK, Elankovan P (1999) Biotechnology of succinic acid production and markets for derived industrial products. Appl Microbiol Biotechnol 51:545-552

Znad H, Markos J, Bales V (2004) Production of gluconic acid from glucose by Aspergillus niger: growth and non-growth conditions. Proc Biochem 39:1341-1345 